\title{
AC 2010-657: A META ANALYSIS OF STUDIES OF COGNITION IN ENGINEERING EDUCATION
}

\section{Terry Brumback, University of Alabama}

Randal Schumacker, The University of Alabama

Daniel Fonseca, The University of Alabama 


\title{
A Meta Analysis of Studies of Cognition in Engineering Education
}

\begin{abstract}
This study is a survey of current literature related to cognition in engineering education. The extensiveness of current empirical evidence is examined and the magnitude and direction of recent studies is determined. The study also examined procedural and cognitive characteristics that might indicate a relationship between cognition and student outcomes. The study represents an extensive search of 27,464 published studies from 10 library holdings and 10 Journals in engineering education. Twenty studies, meeting study criteria, were coded for 39 variables in six categories. Studies were assigned to one of two groups based on the statistical evidence that was reported. Group I reported p-values only and Group II reported F, $t$, or chi square values. Significance of Group I studies is shown through a summary chi square and $p$ value. A summary weighted unbiased effect size was determined for Group II studies. With only $0.07 \%$ of studies meeting search criteria, it was determined that there is a limited amount of empirical evidence in this area of study. Both Group I and Group II studies indicated that there is a positive relationship between cognition and undergraduate engineering student outcomes. There was not enough evidence to suggest a trend between procedural characteristics and cognitive characteristics to student outcomes in undergraduate student outcomes.
\end{abstract}

\section{Introduction}

Engineering education has, in the past, typically referred to those educational programs leading to a professional degree in engineering. A number of degrees are offered in this career field including Bachelor of Science, Master of Science, and Doctor of Philosophy. Lately a number of degree programs have been developed at the Associate of Science level in engineering technologies. Engineering education is typically comprised of multiple disciplines such as industrial, mechanical, civil, electrical, and other specialties. Program graduates in applicable disiplines are eligible to sit for the Professional Engineer (PE) exam after completing the Bachelor of Science degree and ive years of verified field experience.

Engineering education has taken on additional meaning as an engineering iscipline with the establishment of departments such as Freshman Engineering Programs and the less common Engineering Education, in many schools across the country. This move defines the widening responsibility felt by engineering schools to conduct research in areas such as social responsibility, ethics, learning, and retention as the overall demand fo moved from the defense needs of the cold war era to the explosive rise of global competition (National Research Council Board for Engineering Education, 1995). The need for change was initially recognized in three separate reports targeting engineering education (American Society for Engineering Education [ASEE], 1994); National Science Foundation [NSF], 1995; and National Research Council Board for Engineering Education, 1995). Since those initial studies, other reports have called for more specific changes related to teaching and curriculum to support a more diverse group of learners (Building Engineering and Science Talent [BEST], 2004; 
National Academy of Engineering, 2004; and National Academy of Engineering, 2005). Paralleling the call for change in engineering education was the work of independent engineers and educators working in the field (Wulf, 1998; Fromm, 2003; and Slitt, 2003).

Dede (1995) recognized the need to incorporate cognitive science in engineering education. This need was further defined by the National Research Council (2000) through the call for the incorporation of active learning, scaffolding, cooperative learning, and situated learning in educational programs. This represented a shift in strategy (Ditcher, 2001) in how engineering education should be structured.

The Accreditation Board for Engineering and Technology (ABET) (2006) adapted two cognitive models for incorporation into engineering classrooms. Incorporation of Bloom's taxonomy and a modification of the Kolb Learning Cycle were necessary to show alignment with ABET criteria.

The 2006 ABET Criteria marked a decisive change in the direction of engineering education. While earlier calls for change were in the form of recommendations, the ABET criteria represented a requirement for continued accreditation. This joined with the specific talents and recognition engineer educators bring to the incorporation of cognitive science in the classroom and the relative newness of the subject matter, make this a productive area of study.

The purpose of this study is to synthesize, through a meta-analysis study, recent quantitative research on the effects of the incorporation of cognitive science on student outcomes in undergraduate engineering education. As such, this meta-analysis addresses four research questions:

- How extensive is the empirical evidence on the association between cognitive science and student outcomes in engineering education at the undergraduate level?

- What is the magnitude and direction of the association between cognitive science and student outcomes in engineering education at the undergraduate level?

- Are there particular procedural characteristics that affect this study?

- Are there specific characteristics of cognitive science that affect this relationship?

\section{Meta-Analysis Methodology}

\section{Literature Search Procedures}

The literature search included a wide variety of electronic and print resources to identify references for inclusion in the study, including Dissertation Abstracts International, ASEE (American Society of Engineering Education) associated journals, and a thorough search of library holding of 10 individual university libraries. In addition, reference sections of the innumerable studies that were collected were reviewed to identify other potential pertinent research. Finally, several researchers and practitioners, currently working in the field, were contacted and asked to provide relevant research or to identify sources of studies. 


\section{Inclusion Criteria}

Studies were examined to determine whether they met the criteria for inclusion in the study. First, the study examined students enrolled in undergraduate programs enrolled in engineering degree programs at accredited postsecondary institutions in North America and Europe. Second, the study examined the effect of educational programs on the cognitive development of study participants. Third, only studies that were carried out in a classroom or program setting were considered, as opposed to those conducted in a more controlled experimental setting. Fourth, the research was published or reported after 1996, so that the research would more closely reflect the current environment in which students learn. Fifth, and finally, the research reported enough statistical information to estimate either summary chi square or effect size measures.

\section{Variables Studied}

Six categories of variables were studied in this meta-analysis:
1. Characteristics of each study
2. Quality of study indicators
3. Effect size information
4. Indicators of Validity
5. Cognitive characteristics
6. Coding characteristics

Each category consists of a number of variables designed to address the research questions of the study. Appendix A describes the coding variables for each of the six categories.

The study characteristics category variables describe each study included in the meta-analysis. And, the quality of study indicators category variables describes the quality of the research itself.

The effect size information category defines variables related to the calculation of the effect size. This includes effect size $(r)$, effect size $(d)$, and weighted unbiased effect size () calculated by the Meta-Analysis Software Program (Schumacker and Ackers, 2001).

Variables that establish internal and external validity are defined in the indicators of validity category, while, the cognitive characteristics category variables describe teacher/student and learning interactions. The final category, coding characteristics, indicates which studies meet the criteria for inclusion in the meta-analysis study and why those that do not are rejected.

\section{Data Analysis Procedure}

The Meta-Analysis Software Program was used to calculate individual and summary statistics for this study. For processing, studies were assigned to one of two groups: Group I included studies reporting $p$-values only and Group II reported F, $p$, and Chi Square values. For Group I, the significance of the combined studies was indicated by a summary chi square $(x 2)$ and a reported summary $p$-value. For Group II studies, through the software $r$ and $d$ effect size 
measures are calculated for individual studies. These values form the basis for the calculation of, and the weighted unbiased effect size. The weighted unbiased effect size is a bias corrected variation of Cohen's $d$ that takes into account the different sample sizes from the research studies when averaging the $d$ effect size. It was developed separately by L. Hedges, R. Rosenthal, and D. Rubin in 1982.

Findings from the examination of variables indicated in Appendix A from eligible studies were recorded in pencil on code sheets before transferring to an excel spread sheet. Statistical values from the individual studies were then input into the Meta-Analysis Software Program by Group membership.

The basic approach followed in conducting a meta-analysis across several related research studies where only $p$-values are reported was to determine if there was an overall significant effect. The log of $\mathrm{p}$-values from individual studies was used to determine a summary chi-square value. Significance of the combined studies was indicated by the chi-square value. The chisquare value was tested for significance using $2 \mathrm{n}$ degrees of freedom to determine the overall effect across the different research studies. This approach is summarized by Equation 1.

$$
\begin{aligned}
& x^{2}=-2 \sum\left(\log _{\mathrm{e}} \mathrm{p}\right) \\
& \mathrm{df}=2 \mathrm{n} \\
& \text { where } \mathrm{n}=\text { the total number of studies }
\end{aligned}
$$

\section{Equation 1}

In Group II studies, there was no common statistical indicator for the studies as a whole. This required that each study be placed on a common metric. To eliminate this issue, both effect size (r) and effect size (d) were calculated using Equations 2a-c, and 3a-c.

$$
r=\sqrt{\frac{t^{2}}{t^{2}+d f}} \quad r=\sqrt{\frac{F^{2}}{F+d f_{\text {crror }}}} \quad r=\sqrt{\frac{x^{2}}{n}}
$$

(a)

(b)

(c)

Equation 2

$$
\begin{array}{|c|c|c|}
\hline d=\frac{2 t}{\sqrt{d f}} & d=\frac{2 \sqrt{F}}{\sqrt{d f_{\text {error }}}} & d=\frac{2 r}{1-r^{2}} \\
\hline
\end{array}
$$

\section{Equation 3}

Other concerns related to the effect that different sample sizes had on the interpretation of the meta-analysis. Procedures for incorporating different sample sizes into a single analysis, when determining effect size estimates, were incorporated into the software. 
After effect sizes for all outcomes in the individual studies are calculated $r$ and $d$ are calculated using equations $4 \mathrm{a}$ and $4 \mathrm{~b}$ respectively.

$$
\begin{array}{|l|l|}
\hline r=\frac{\sum r}{n} & \bar{d}=\frac{\sum d}{n} \\
\hline
\end{array}
$$

(a)

(b)

\section{Equation 4}

The weighted unbiased $w$ was then calculated, equation 5a, followed by the weighted unbiased () effect size, equation $5 b$. d

$$
\begin{array}{|l|l|}
\hline w=\frac{2 n}{8+d^{2}} & \bar{d}=\frac{\sum w d}{\sum w} \\
\hline
\end{array}
$$

(a)

(b)

\section{Equation 5}

A search of 32 engineering education journals, Dissertation Abstracts Direct, and holdings from 10 university libraries realized 27,464 studies that resulted in 218 studies that appeared to meet the search criteria. A closer review indicated that 198 of these studies failed to meet all specifications of the search criteria. The remaining 20 studies met all specifications for inclusion in the study.

A total of 56 outcome measures were coded from the remaining 20 studies by a single individual, eliminating issues with inter-rater reliability. Each outcome was coded for 39 variables in six categories: 1) characteristics of each study, 2) quality of study indicators, 3) effect size information, 4) indicators of validity, 5) cognitive characteristics, and 6) coding characteristics.

The 20 studies were categorized into two groups based on reported statistical indicators. Ten studies, which reported $p$ values only, were designated as Group 1. The remaining studies, which reported F, $t$, or Chi Square (x2) values, were designated as Group 2. Groups were analyzed separately using the Meta Analysis Software Program.

Characteristics of the study indicated that individual studies were carried out by 61 researchers located at 34 separate institutions. The studies were published in 10 different research journals. Engineering disciplines represented in the studies were mechanical, industrial, chemical, electrical, freshman studies, and general engineering studies.

Of the 20 studies included in the meta-analysis, $20 \%$ were published before $2000,70 \%$ were published in the past five years, and $40 \%$ were published in the last three years. When compared with the large number of studies rejected for failure to meet inclusion criteria, a larger number of 
studies based on empirical findings are beginning to emerge. Should this trend continue it can be expected that a larger body of research will be available in the future.

In the quality of study indicators category, $95 \%$ of studies were classified as quasi-experimental designs while 5\% were experimental designs. Equivalency of groups was established in $40 \%$ of studies. Pre-test/post-test was the format of scores in 35\% of studies with the remainder relying on a single end of treatment score. Reliability was established in $35 \%$ of studies.

Group 1 consists of 10 studies reporting $p$-value as a statistical indicator. Indicators were entered into the Meta-Analysis Software Package. The log of p-values from individual studies was used to determine a summary chi-square value of $82.866, p=0.0001$. The significance of the combined studies was indicated by the chi-square value. The chi-square value was tested for significance using $2 \mathrm{n}$ degrees of freedom to determine the overall effect across the different research studies. Group 1 results are summarized in Table 1.

\begin{tabular}{|ll|}
\hline Research Study & Fisher ln (p) \\
Contero et al., 2005 & -3.381 \\
Dessouky et al., 1998 & -3.912 \\
Dori and Belcher, 2005 & -3.058 \\
Jensen et al., 2002 & -3.381 \\
Linsenmeier et al., 2008 & -4.017 \\
Oliver-Hoyo, 2004 & -2.291 \\
Pandy et al, 2004 & -4.828 \\
Record, 2005 & -6.908 \\
Roselli \&Brophy, 2006 & -2.749 \\
Taraban et al., 2007 & -6.908 \\
\hline \multicolumn{2}{|c|}{ Summary Chi Square= 82.866, df $=20}$, \\
p= 0.0001 \\
Summary of Group 1 Findings \\
Table 1
\end{tabular}

Studies included in Group 2 reported F, $t$, and Chi Square statistical indicators. These indicators were input into the software package. To put all indicators on a common scale, $\mathrm{r}$ and $\mathrm{d}$ effect sizes were calculated for each study. Summary statistics $r$ and $d$, and the weighted unbiased $d$ summary statistics were reported: effect size $(r)=0.408$, effect size $(d)=1.203$, and the weighted unbiased effect size $(d)=0.792$. Effect sizes and summary statistics for Group 2 are indicated in Table 2.

Active learning environments were indicated in $80 \%$ of studies and $85 \%$ incorporated concepts of structured cognition in the research plan. Scaffolding was indicated in $45 \%$ of studies. Cooperative learning was found in $10 \%$ of studies.

Of the 20 studies selected for the meta-analysis, the research method selected was fitting for $95 \%$ of the studies. The instrumentation selected seemed appropriate for $65 \%$ of studies. There did not 
appear to be an issue with history, maturation, bias, mortality, or selection-maturation interaction. There were no issues related to the ethical conduct of the investigators.

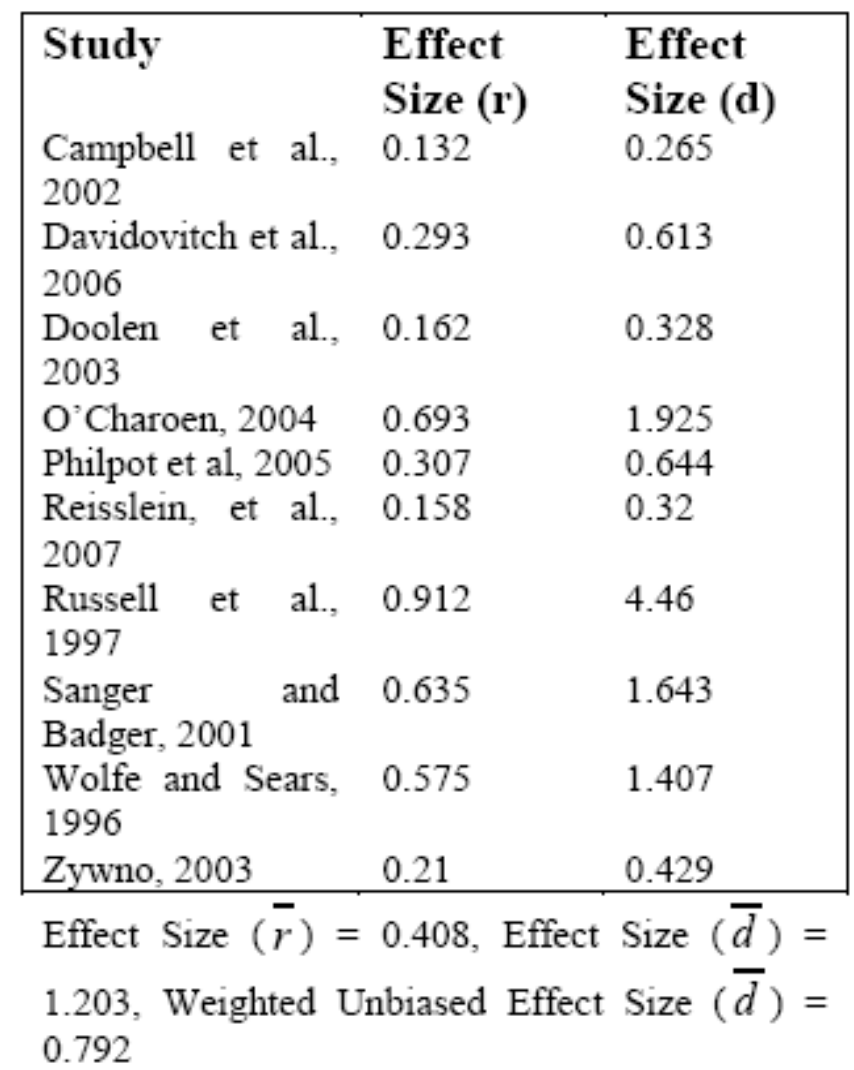

\author{
Summary of Group 2 Findings \\ Table 2
}

\title{
Discussion
}

The empirical evidence on the association between cognitive science and student outcomes in undergraduate engineering education is somewhat limited. This is evidenced by the number of studies that met the inclusion criteria. Of the 27,464 studies that were searched, only 20 or $0.07 \%$ met all of the criteria for this study. While the studies represent a diverse sampling of engineering disciplines, this is not the case with the journals they are published in. Of the ten journals represented in the study, $50 \%$ of the studies are published in the Journal of Engineering Education (JEE), another $10 \%$ are published in JEE sister publications. The studies are somewhat limited in that they do not represent all grade levels, with $20 \%$ directed toward introductory engineering coursework and an additional $75 \%$ aimed at specific concepts within a single engineering course.

For Group I studies, those indicating $p$-vales only, the summary chi square value was $82.866, \mathrm{df}=$ $20, p=0.001$. This indicates that there is a difference between groups integrating cognitive 
science into the classroom. We can therefore accept the hypothesis that cognitive science plays a positive role in undergraduate engineering education outcomes.

Similar results were found in Group II studies, those reporting indicators other than $p$-values, reported a weighted unbiased effect size $(\mathrm{d}$ bar $)=0.792$. This would indicate that the magnitude of the effect size indicates that the effect of cognitive science on student outcomes in undergraduate engineering programs is large.

There were a limited number of cognitive techniques indicated by the study. This could, however, have been related to the reliance of instructors on modeling to learn teaching methods and the limited literature aimed at promoting engineering education. It would be expected, with the growing emphasis on cognitive science in engineering, that this would change as more authors become aware of cognitive models and reporting methods.

The identification of procedural and cognitive science characteristics that affect the relationship between cognitive science and student outcomes could not be answered by the study. This is due primarily to the research plans and reporting methods employed by researchers. While this might seem to be a limitation of current research studies, it offers a direction for the design of future research design. A major of limitation does, however, exist in the study related to the limited number of studies meeting the inclusion criteria. Such a limitation makes it difficult to generalize the results to specific areas within the study of cognition. This study represents a synthesis of quantitative studies on the effect of cognitive science on student outcomes in engineering education. Its contribution lies in the recognition that cognitive science offers a means to positively affect student outcomes and that it provides a baseline to compare similiar future studies against. This has implications in both the number and quality of engineers that are produced in today's global economy.

The study has further reaching effects by indicating an alternate methodology to instructors who are looking to improve instruction and administrators who allocate monies to research project.

\section{Bibliography}

The Accreditation Board for Engineering and Technology (ABET). (2006). Program criteria. Retrieved 9-16-2008 from http://www.abet.org

American Society for Engineering Education (ASEE). (1994). Engineering education for a changing world. ASEE Deans Council and Corporate Roundtable. Washington, DC: ASEE.

Building Engineering and Science Talent (BEST). (2005). A bridge for all: Higher education design principles to broaden participation in science, technology, engineering, and mathematics. Retrieved 10-25-2008 from http://www.bestworkforce.org

Campbell, J.O., Bourne, J.R., Moserman, P.J., \& Brodersen, A.J. (2002). The effectiveness of learning simulations for electronic laboratories. Journal of Engineering Education, 91, 81-87. 
Davidovitch, L., Parush, A. and Shtub, A. ( 2006). Simulation-based learning in engineering education: Performance and transfer in learning project management. Journal of Engineering Education, 95(40), 289-299.

Dede, C. (1995). Artificial realities, virtual communities, and intelligent artifacts: Implications for engineering education. In J.R. Bourne, A. Brodersen, \& M. Dawant (Eds), The influence of technology on engineering education (pp. 36-65). Boca Raton, FL: CRC Press.

Dessouky, M.M., Bailey, D.E., Verma, S., Adiga, S., Bekey, G.A., \& Kazlauska, E. J. (1998). A virtual factory teaching system in support of manufacturing education. Journal of Engineering Education, 87(4), 459-467.

Ditcher, A.K. (2001). Effective teaching and learning in higher education, with particular reference to the undergraduate professional education of professional engineers. International Journal of Engineering Education, 87, 459-467.

Doolen, T.L., Porter, J.D., \& Hoag, J. (2003). The relationship between PDA usage and student performance in an introductory engineering course. Journal of Engineering Education, 92, 263268.

Dori, Y.D., \& Belcher, J. (2005). How does technology-enabled active learning affect undergraduate students' understanding of electromagnetism concepts? Journal of the Learning Sciences, 14, 243-279.

Fromm, E. (2003). The changing engineering educational paradigm. Journal of Engineering Education, 92, 113-121.

Jensen, D., Self, B., Rhymer, D., Wood, J., \& Bowe, M. (2002). A rocky journey toward effective assessment of visualization modules for learning enhancement in engineering mechanics. Educational Technology and Society, 5(3), 150-162.

Linsenmeier, R.A., Kanter, D.E., Smith, H.D., Linsenmeier, K.A., \& McKenna, A.F. (2008). Evaluation of a challenge-based human metabolism laboratory for undergraduates. Journal of Engineering Education, 97(2), 213-222.

National Academy of Engineering. (2004). The engineer of 2020: Visions of engineering in the new century. Washington, DC: National Academy Press.

National Academy of Engineering. (200). Educating the engineer of 2020: Adapting engineering education to the new century. Washington, DC: National Academy Press. National Research Council. (2000). How people learn: Brain, mind, experience, and school. Washington DC: National Academy Press. 
National Research Council Board for Engineering Education. (1995). Engineering education: Designing an adaptive system. Washington DC: National Academy Press.

National Science Foundation (NSF). (1995). Restructuring engineering education: A focus on change. Report of an NSF Workshop on Engineering Education, June 6-9, 1994. Arlington, VA.

O'Charoen, V. (2004). Computer based instruction for modular fixturing design instruction. Journal of Engineering Education, 14(4), 88-89.

Oliver-Hoyo, M.T., Allen, D., Hunt, W.F., Hutson, J., \& Pitts, A. (2004). Effects of an active learning environment: Teaching innovations at a Research I institution. Journal of Chemical Education, 81, 441-448.

Pandy, M.G., Petrosino, A.J., Austin, B.A., \& Barr, R.E. (2004). Assessing adaptive expertise in undergraduate biomechanics. Journal of Engineering Education, 93, 211-222.

Philpot, T.A., Hall, R.H., Hubing, N., \& Flori, R.E. (2005). Using games to teach statics calculation procedures: Applications and assessment. Computer Applications in Engineering Education, 13, 222-232.

Reisslein, J.., Sullivan, H., \& Reisslein, M. (2007). Learner achievement and attitudes under different paces of transitioning to independent problem solving. Journal of Engineering Education, 96(1), 45-55.

Record, P. (2005). Teaching the art of fault diagnosis in electronics by a virtual learning environment. IEEE Transactions on Education, 48, 375-381.

Roselli, R.J. \& Brophy, S.P. (2006). Effectiveness of challenge-based instruction in biomechanics. Journal of Engineering Education, 95(4), 311-324.

Russell, J.W., Kozma, R.B., Jones, T., Wykoff, J., Marx, N., \& Davis, J. (1997). Use of simultaneous-synchronized macroscopic, microscopic, and symbolic representations to enhance teaching and learning of chemical concepts. Journal of Chemical Education, 74, 330-334.

Sanger, M.J., \& Badger, S.M.I. (2001). Using computer-based visualization strategies to improve students' understanding of molecular polarity and miscibility. Journal of Chemical Education, $78,1412-1416$.

Schumacker, R.E. \& Akers, A. (2001). Understanding statistical concepts using s plus. New Jersey: Lawrence Erlbaum Associates.

Splitt, F.G. (2003). The challenge to change: On realizing the new paradigm for engineering education. Journal of Engineering Education, 92, 181-187. 
Taraban, R., Anderson, E.E., DeFinis, A., Brown, A.G., Weigold, A., \& Sharma, M.P. (2007). First steps in understanding engineering students' growth of conceptual and procedural knowledge in an interactive learning context. Journal of Engineering Education, 96(1), 57-68.

Villareal, S., Eastwood, D., Seetharam, A., \& Wynn, C. (1998). Design, development, and impact of computer-animated simulations of diode rectifiers. Computers in Education Journal, 8(4), 56-60. Wolfe, R., \& Sears, A. (1996). Effective tool for learning the visual effects of rendering algorithms. Computer Graphics (ACM), 30(3), 54-75.

Wulf, W.A. (1998). The urgency of engineering education reform. The Bridge of the national Academy of Engineering, 28(1), 4-8. Zywno, M.S. (2003). Hypermedia instruction and learning outcomes at different levels of Bloom's taxonomy of cognitive domain. Global Journal of Engineering Education, 7, 59-70. 
Appendix A

\begin{tabular}{|c|c|c|c|}
\hline Category Number & Category & Number of Variables & Description of Variables \\
\hline 1 & Study Characteristics & 11 & $\begin{array}{ll}\text { 1. } & \text { Unique Identifier } \\
\text { 2. } & \text { Author } \\
\text { 3. } & \text { Year } \\
\text { 4. } & \text { Title } \\
\text { 5. } & \text { Journal } \\
\text { 6. } & \text { Publication Type } \\
\text { 7. } & \text { Eng. Content Area } \\
\text { 8. } & \text { Sample Size } \\
\text { 9. } & \text { Sample Size (Control } \\
& \text { Group) } \\
\text { 10. } & \text { Sample Size } \\
& \text { (Experimental Group) } \\
\text { 11. } & \text { Unit of Analysis }\end{array}$ \\
\hline Category Number & Category & Number of Variables & Description of Variables \\
\hline 2 & Quality of Study Indicators & 8 & $\begin{array}{ll}\text { 1. } & \text { Research Design } \\
\text { 2. } & \text { Participant Assignment } \\
\text { 3. } & \text { Equivalence of Group } \\
& \text { Established } \\
\text { 4. } & \text { Reliability Statistic } \\
\text { 5. } & \text { Format of Scores } \\
\text { 6. } & \text { Statistical Indicator } \\
\text { 7. } & \text { Source of Cognitive } \\
& \text { Measurement } \\
\text { 8. } & \text { Type of Outcome } \\
& \text { Measurement } \\
\end{array}$ \\
\hline Category Number & Category & Number of Variables & Description of Variables \\
\hline 3 & Effect Size Information & 3 & $\begin{array}{ll}\text { 1. } & \text { Effect Size Coefficient } \\
\text { 2. Statistic Used in the } \\
\text { Calculation of Effect } \\
\text { Size } \\
\text { 3. Effect Size }\end{array}$ \\
\hline Category Number & Category & Number of Variables & Description of Variables \\
\hline 4 & Invalidity & 8 & $\begin{array}{ll}\text { 1. } & \text { History } \\
\text { 2. } & \text { Maturation } \\
\text { 3. } & \text { Testing } \\
\text { 4. } & \text { Instrumentation } \\
\text { 5. } & \text { Bias } \\
\text { 6. } & \text { Mortality } \\
\text { 7. } & \text { Selection-Maturation } \\
& \text { Interaction } \\
\text { 8. } & \text { Statistical Power } \\
\end{array}$ \\
\hline FigurCategory Number & Category & Number of Variables & Description of Variables \\
\hline 5 & Teaching Characteristics & 6 & $\begin{array}{ll}\text { 1. } & \text { Interactive Learning } \\
\text { 2. } & \text { Experiences } \\
\text { 3. } & \text { Miteracy Development } \\
\text { 4. } & \text { Cognitive Development } \\
\text { 5. } & \text { Mode of Instruction } \\
\text { 6. } & \text { Role of Instructor }\end{array}$ \\
\hline Category Number & Category & Number of Variables & Description of Variables \\
\hline 6 & Coding Characteristics & 3 & $\begin{array}{ll}\text { 1. } & \text { Meets Inclusion Criteria } \\
\text { for Meta-Analysis } \\
\text { 2. Reason for } \\
\text { Disqualification } \\
\text { 3. } \text { Comments } \\
\end{array}$ \\
\hline
\end{tabular}

